\title{
Design of Warehouse Management Experiment Based on the Combination of Virtuality and Reality
}

\author{
Xiulian $\mathrm{Hu}^{1,2, *}$ and Yi-Fei Chuang ${ }^{2}$ \\ ${ }^{\text {IS }}$ chool of Economics and Management, Fuzhou University of International Studies and Trade, Fuzhou, Fujian 350202, \\ China \\ ${ }^{2}$ Department of Business Administration, Ming Chuan University, Taipei, Taiwan 7400, China \\ *Corresponding author. Email: huxiulian2007@163.com
}

\begin{abstract}
For the purpose of cultivating and bringing up application-oriented warehouse management talents, this paper points out the pain points of warehouse management experiment on the basis of analyzing the teaching status of logistics management specialty, and puts forward an experimental teaching mode of warehouse management combining virtual and real. Firstly, students design the warehouse management scheme according to the virtual case. Then Then they implement their own scheme on the online experimental platform and offline supporting storage equipment, and carry out the virtual and real combination of sorting and inventory management operations. Finally, they verify their mastery of knowledge through experimental results. Through the implementation of this teaching model, students' ability to analyze and solve problems with warehouse management knowledge has been significantly improved.
\end{abstract}

Keywords: virtuality and reality combination; experimental design; warehouse management; experiment teaching

\section{INTRODUCTION}

In recent years, under the promotion of the rapid development of e-commerce, China's logistics industry has developed rapidly. The demand for logistics has increased year by year, and there is a gap in the demand for logistics talents. However, the employment situation of students is still not optimistic. The main reason is that there is a gap between the training of schools and the needs of society. What society needs are comprehensive talents with both theory and practice, and most colleges and universities focus on training talents with theoretical knowledge. Therefore, in order to meet the needs of society, in the future logistics talent training process, logistics management students not only need to have comprehensive and professional theoretical knowledge, but also need to cultivate practical and practical skills. However, due to the short running time, shortage of funds and many other reasons, practical teaching is the weakest part of the entire teaching system of logistics management. How to promote the practical teaching process of logistics management in accordance with the needs of enterprises and society for the practical ability of logistics talents has become an urgent problem to be solved in the teaching and development of logistics management.

\section{LITERATURE REVIEW}

In terms of practical teaching of logistics management, some developed countries in the West attach importance to experimental links and the cultivation of students' professional abilities. For example, the University of California, Massachusetts Institute of Technology in the United States, the University of Munich, and the University of Cologne in Germany have established advanced logistics laboratories. They have in-depth research and practice in experimental teaching, and cultivate a large number of comprehensive talents with professional capabilities. . Many advanced experiences of these universities are worth learning from. In China, the state clearly requires "strengthening practical teaching and improving the practical ability of college students." The state and universities are paying more and more attention to the development of experimental teaching and increasing investment in laboratory construction. On the other hand, with the increasing demand for comprehensive ability-oriented logistics talents in today's society, the status and role of logistics experiments in teaching are also increasing.

In recent years, various colleges and universities have been different in logistics laboratory construction and teaching planning based on their own subject foundation and schoolrunning characteristics, however, the development of experimental projects is mostly based on two main forms. One is a software platform based on integrated logistics information services. This is generally a mechanical 
running process. It is difficult for students to associate the information process with actual logistics operations. The second is the use of logistics hardware equipment and facilities, but due to the limitations of laboratory space and capital investment, the experimental environment created is generally relatively simple and can only demonstrate some basic operating procedures. In order to overcome their respective shortcomings, many colleges and universities have introduced some virtual simulation logistics software. Gao Jun (2011) introduced a logistics experiment and practice teaching model that uses virtual simulation technology to build a visual simulation experiment environment. Combining with traditional logistics experiment teaching methods, the author proposes how to carry out logistics experiments and practical teaching in a virtual simulation environment. It not only allows students to be familiar with the experimental functions of facilities and equipment, simulation operation, verification decisionmaking, organization and management, but also realizes the purpose of avoiding misoperation accidents and simulation operation dangerous experiments [1]. Lin Qiuping (2016) designed a set of teaching system that combines theory and practice based on computer simulation software and combined with project-driven teaching methods. The teaching system takes specific logistics experiment projects as the object, and divides the main teaching process into four parts: research object system, data processing, construction of system computer simulation model, and system output analysis [2]. Chen Weiwei (2017) introduces 3D simulation technology into logistics experimental teaching, allowing students to explore and learn in a simulated situation, give full play to the students' subjective initiative, and entertaining [3]. Through human-computer interaction, professional skills can be mastered faster, and students' practical ability, independent thinking ability, innovative thinking ability, unity and cooperation ability and comprehensive quality can be improved. Virtual experiments are known laws obtained from physical experiments through computer simulation, but it cannot simulate certain abnormal phenomena and failures that may occur in physical experiments, and it cannot completely simulate and replace the cognitive experience of humans interacting with the objective world.

Wang Chenglin (2010) thought that the current logistics experimental teaching has some problems, such as the experimental teaching system is not systematic enough, the experimental content needs to be improved, the utilization rate of experimental implementation equipment is not high, the evaluation system of the whole experiment process is not perfect, the experimental teaching means are not rich, and the management method of experimental teaching is not scientific enough, and puts forward corresponding improvement strategies [4]. Wang Dongliang (2017) proposed a question-inquiry-based logistics experimental teaching system, and combined with teaching practice, discussed the application of question-inquiry method in logistics experimental teaching [5]. Yao Qi (2017) explained the necessity of strengthening the reform of experimental teaching system of logistics management specialty, and systematically explored the relevant measures to strengthen the reform of experimental teaching system of logistics management specialty from the aspects of setting experimental content, strengthening project guidance and introducing school enterprise joint teaching mode [6]. According to the characteristics of logistics management specialty, Chen ailing (2017) proposed an experimental teaching system of logistics management specialty based on comprehensive experimental platform. The system determined the requirements and objectives of the experimental teaching system of logistics management specialty based on the ability system, and designed the content of the experimental teaching system and the assessment and evaluation criteria of the experimental teaching link [7].

At present, the teaching methods used in the process of logistics experiment teaching are relatively simple. For software courses, teachers mainly use multimedia demonstration teaching, and students practice to master the use of software. Hardware experimental teaching often focuses on the demonstration of equipment, students' sense of participation is not strong, in the teaching process, students often dissociate from the teaching system[8-10].

\section{PAIN POINTS OF WAREHOUSE MANAGEMENT EXPERIMENTS}

\section{1. "Four Flows" Separation}

Many warehousing management experimental designs only involve part of the links of information flow, business flow, logistics, and capital flow, without systematic integration of these links. Software and hardware systems cannot be interconnected to complete the warehouse management experiment teaching, and cannot truly simulate a complete warehouse management training scene.

\subsection{Information Island}

The warehouse management experiment was not designed and planned with an information closed-loop warehouse management business model, which resulted in the inconsistent information flow of each link of the warehouse management experiment, which caused the teacher to encounter a bottleneck in the continuity of comprehensive teaching. Students are prone to fall into misunderstandings in learning, and it is difficult to understand the overall operation process and management ideas of the warehouse. Therefore, this article adheres to the concept of "combination of virtuality and reality, complements each other, and can not be virtual". Aiming at the seven major links of warehousing operations, a model of experimental teaching combining virtual and actual is proposed. Through the systematic and overall experimental teaching design, 
the experimental teaching content and various elements in the experimental process are reasonably arranged, the virtual experiment and the real experiment are effectively integrated, and an open storage operation simulation experiment teaching platform is constructed.

\section{EXPERIMENTAL DESIGN BASED ON THE COMBINATION OF VIRTUALITY AND REALITY}

The combination of virtual and actual experimental teaching refers to simulating the actual situation of different companies by simulating online orders and simulating scenarios of the electronic mall, so that students can use professional knowledge to think and analyze problems independently, and then put forward solutions. Then carry out the implementation and hands-on operation of the scheme on the open experimental platform, and finally obtain the real data results, which are compared and verified with the expected results, so as to test the students' understanding, mastery and application of knowledge.

"Virtuality" refers to giving students a virtual shopping on an e-commerce shopping platform or using virtual enterprise background cases to simulate corresponding warehouse management tasks. In this way, we can simulate different warehousing and logistics demand scenarios, and we can also choose to send logistics or express delivery according to different actual conditions. "Reality " means that students use planting walls, shelves, electronic tags, conveyor belts, RFID and other facilities and equipment to actually perform order processing operations, purchasing operations, warehousing operations, inventory operations, picking operations, outgoing operations, and distribution operations. We can also get the actual data of the students' experiments.

The design idea of this experiment is shown in Fig. 1. Firstly, through the design of virtual case background and virtual shopping on e-commerce platform, different actual business conditions are simulated, so that students can apply the professional knowledge of warehouse management to independently analyze problems and propose solutions. Then implement their own schemes on the open experimental platform to carry out sorting operations and inventory management operations combining virtuality and reality. Finally, the real data results are obtained, which are compared and verified with the expected results, so as to test their understanding and application ability of warehouse management knowledge.

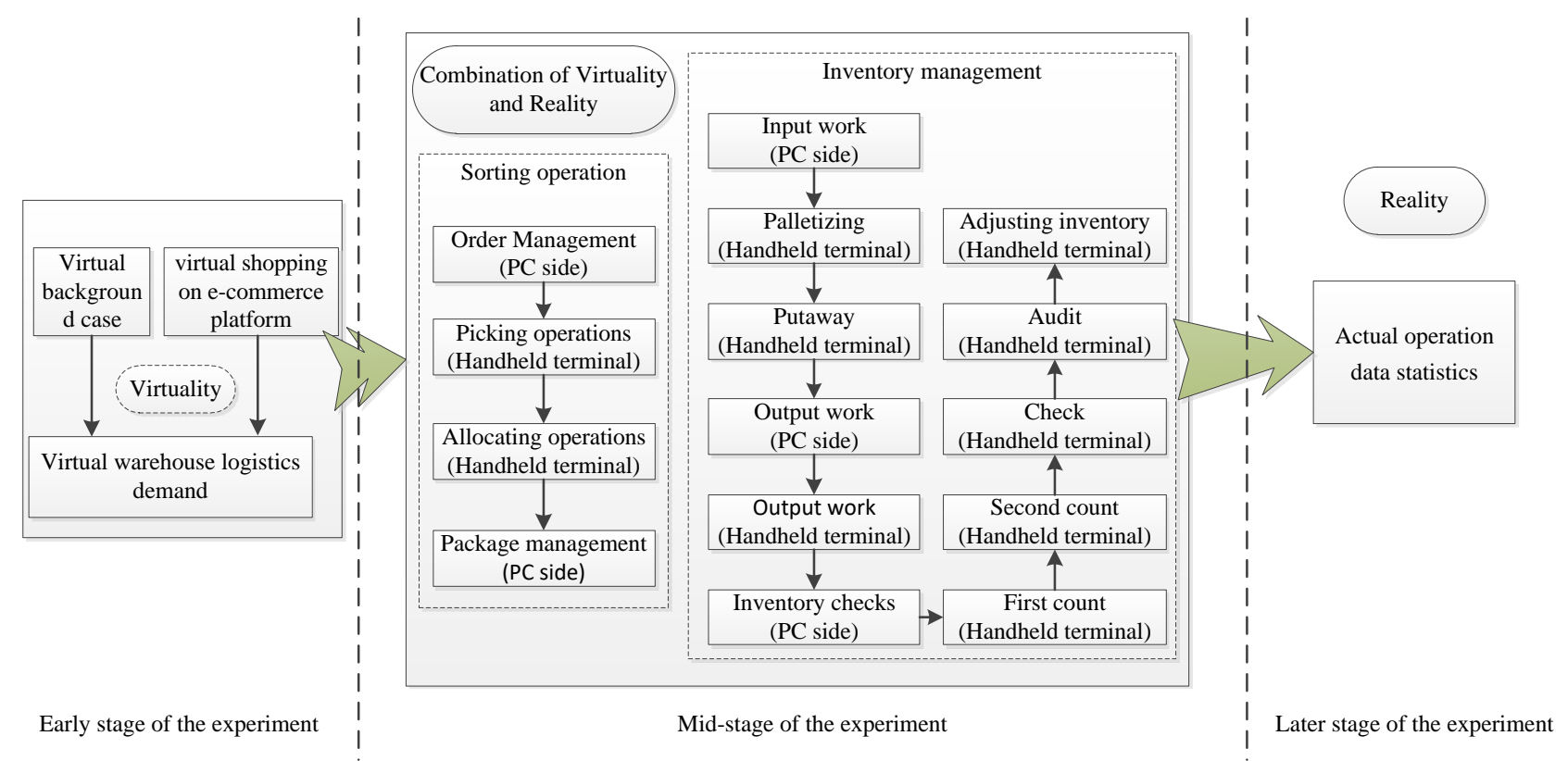

Figure 1. The design idea of warehouse management experiment based on the combination of virtuality and reality.

The experiment is carried out in two stages. In the first stage, according to the simulated order information of the mall platform, order analysis is carried out, combined with the on-site shelf layout, the group discusses and designs a reasonable picking plan, and then the order picking information process is operated on the PC side of the ecommerce distribution platform. And use the handheld terminal to pick the goods in the corresponding cargo area, perform the operation of information flow and logistics, and finally complete the implementation of the entire picking plan. In the second stage, based on the warehousing requirements generated by the simulation case, team members design a reasonable warehousing management plan, and complete the operation of 
warehousing information flow on the $\mathrm{PC}$ side of the ecommerce warehousing platform. Then use the handheld terminal to the warehouse to realize the operation of the information flow and logistics of the operations such as warehousing, inventory checking and warehouse adjustment.

Through practical training, students can master the information flow, logistics operation and actual operation process of e-commerce distribution and warehouse management. The main business functions include receiving orders from customers, central distribution, regional distribution, front-end distribution, and integrating hardware equipment such as SMS, barcode scanner and BOX-ID. To enable students to understand the business of in and out of warehouse, sorting, allocation, and distribution, and master the methods of distribution and sorting and warehouse management using information systems.

This kind of storage management experiment combining virtuality and reality promotes the cultivation of students' learning ability. Under this experimental teaching mode, students are no longer passive receivers of knowledge, but become active explorers of knowledge. It not only enhances students' independent learning ability, but also enhances students' interest in learning. Using this experimental teaching mode, students no longer face boring hardware devices or virtual simulation software, but face simulations of real data, design their own implementation plans, and conduct information flow and logistics operations in the actual warehousing process. The combination of hardware and software enhances the attractiveness of students.

\section{EXTENSION OF THE EXPERIMENTAL PLATFORM}

Relying on the warehousing management experimental platform to develop experimental projects that are continuous and can meet the needs of different courses (such as E-commerce, transportation management, logistics facilities and equipment) at different levels. So as to build a diversified experimental curriculum system, comprehensive and open experimental exploration and practice are carried out on this platform, as shown in Fig. 2. In the "E-commerce" course, through the shopping mall platform and mobile shopping platform, students can grasp the flow of business and capital flows, and generate logistics needs for the "warehouse management" experiment. According to the logistics requirements, students can perform related tasks such as order processing, purchasing, warehousing, inventory, picking, outgoing, and delivery. According to production and distribution needs, design experimental projects such as route optimization in the experimental class of "transportation management". At the same time, in the actual operation link of "Logistics Facilities and Equipment" experiment, students are allowed to recognize the planting walls, shelves, electronic tags, conveyor belts, RFID technology and other facilities and equipment.

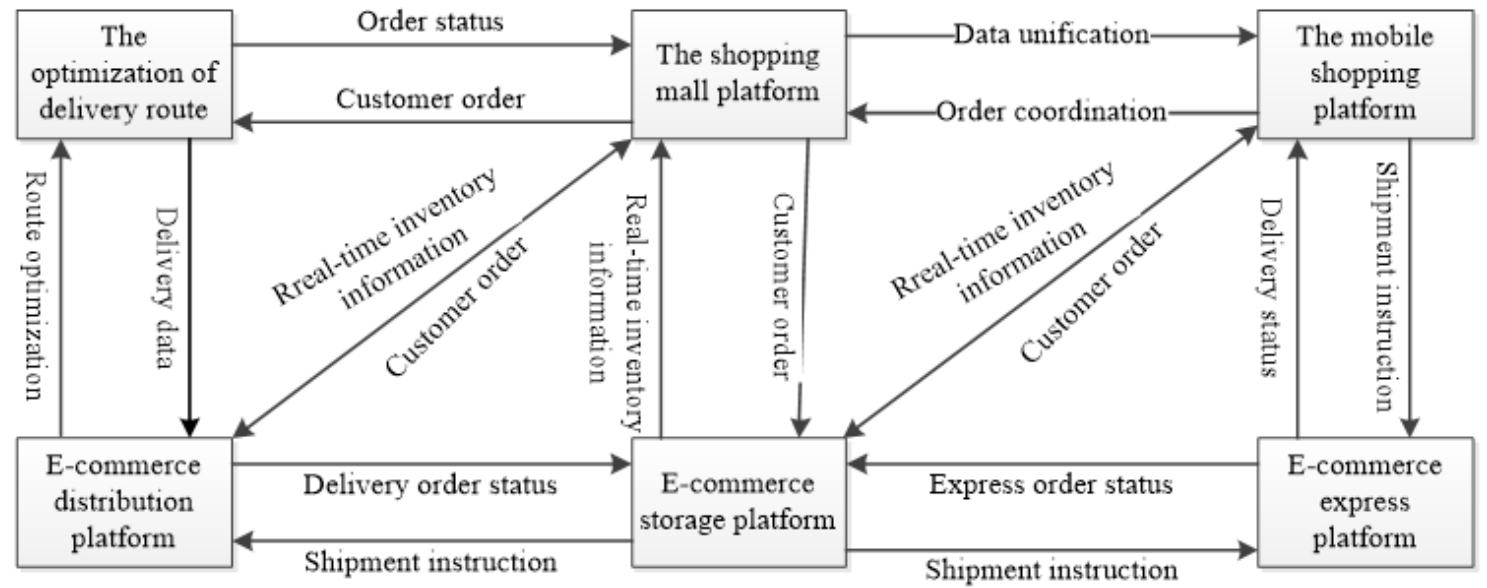

Figure 2. The design idea of warehouse management experiment based on the combination of virtuality and reality.

\section{CONCLUSION}

This article proposes an experimental teaching mode combining virtual and actual for the experimental teaching of logistics warehousing sorting and inventory management operations. Through the systematic and overall experimental teaching design, the experimental teaching content and various elements of the experimental process are reasonably arranged, the virtual experiment and the real experiment are effectively integrated, and an open warehouse management experimental teaching platform is constructed. Moreover, relying on the experimental platform to develop experimental projects with continuity and meet the needs of different levels, build a diversified experimental curriculum system, and conduct comprehensive and open experimental exploration and practice. 


\section{ACKNOWLEDGMENT}

This paper is supported by The 13th Five-Year Plan for Education science of Fujian Province (No. FJJKCG18109).

inning of a sentence.

\section{REFERENCES}

[1] J. Gao, "Organization and application of virtual environment based logistics experiment education," Logistics Technology, vol.30, 2011, pp. 238-239+245. DOI: https://doi.org/ 10.3969/j.issn.1005152X.2011.07.074

[2] Q. P. Lin and Y.H. Li, "Exploration of logistics system simulation modeling experimental teaching," Experimental Technology and Management, vol.33, 2016, pp. 215-217+231. DOI: https://doi.org/ 10.16791/j.cnki.sjg.2016.01.057

[3] W. W. Chen and Z. L. Ma, “Application of 3D interactive simulation teaching Platform in logistics experiment teaching," Heilongjiang Science and Technology Information, vol.14, 2017, pp. 58-59. DOI: https://doi.org/ 10.3969/j.issn.1673-1328.2017.04.055

[4] C. L. Wang, "The present situation and countermeasure analysis of logistics experiment teaching," China Logistics \& Purchasing, vol.4, 2010, pp. 54-55. DOI: https://doi.org/ 10.16079/j.cnki.issn1671-6663.2010.04.009

[5] D. L. Wang, Z. Yan and Z.N.Yu, "Study on problem-based explorative logistics experiment teaching," Logistics Technology, vol.36, 2017, pp. 168-
171+188. DOI: https://doi.org/ 10.3969/j.issn.1005152X.2017.08.039

[6] Q. Yao, "Research on the reform of experimental teaching system of logistics management specialty," Ability And Wisdom, vol.11, 2017, pp. 207-208. DOI: https://doi.org/ CNKI:SUN:CAIZ.0.2017-11-188

[7] A. L. Chen, Y. F. Luo and Y. L. Guo, "Research on experiment teaching system of logistics management education based on integrated experimental platform," Logistics Engineering and Management, vol.39, 2017, pp. 192-194. DOI: https://doi.org/ 10.3969/j.issn.10023100.2017.12.040

[8] W. Wen, W. Y. Ding, A. L. Feng. L. J. Zheng and X. F. Fan, "Implementation of the experiment platform based on AS/RS to SCM," Experimental Technology and Management, vol.25, 2008, pp. 173-176. https://doi.org/10.16791/j.cnki.sjg.2008.06.051

[9] Z. L. Huang, J. X. Chen, “ A Study of Logistic Warehouse Picking Experimental Teaching Base on Combination of Virtual and Real Experiments," Logistics Engineering and Management, vol.38, 2016, pp. 281-284. DOI: https://doi.org/ 10.3969/j.issn.16744993.2016.05.104.

[10] Huang Zhuiliang, Ye Chong. "Study on Establishment of Logistics Warehousing and Distribution Simulation Platform and Multi-level Experiment Teaching Practice," Logistics Technology, vol.31, 2012 pp. 475-477. DOI: https://doi.org/ 10.3969/j.issn.1005-152X.2012.11.151. 